\title{
Aproveitamento de água de aparelhos de ar condicionado em prédio público do
}

\section{estado de Pernambuco}

\author{
Use of water from air conditioning appliances in public building in the state of Pernambuco \\ Uso de agua de aparatos de aire acondicionado en edifício público del Estado de Pernambuco
}

Recebido: 16/11/2021 | Revisado: 24/11/2021 | Aceito: 25/11/2021 | Publicado: 07/12/2021

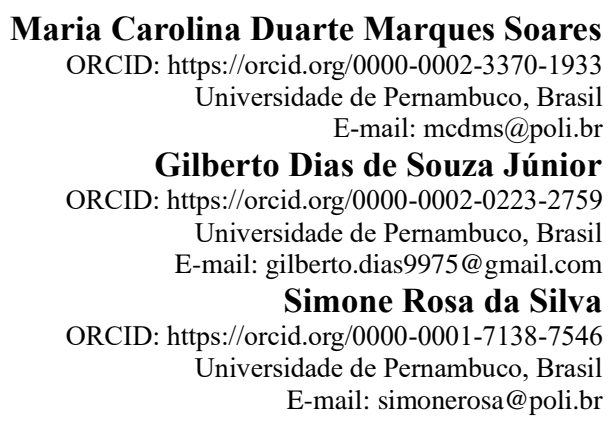

\begin{abstract}
Resumo
Ao longo dos anos em prol do uso racional da água, surge a necessidade de repensar as formas de uso dos recursos hídricos, adotando práticas sustentáveis que visam garantir o futuro das novas gerações. As formas de amenizar os impactos podem ser o reúso e o aproveitamento hídrico, onde se enquadra o aproveitamento de água proveniente dos aparelhos de ar condicionado. O presente trabalho tem o objetivo de avaliar a viabilidade do aproveitamento de água dos equipamentos de ar condicionado do Laboratório Farmacêutico de Pernambuco (LAFEPE). Desta forma, foi tomado como objeto de estudo o prédio de resíduos sólidos 1 do LAFEPE, que conta com 10 aparelhos do tipo Fancoil de capacidade total de 310,50 TR (tonelada de refrigeração). As medições foram feitas de forma direta nos drenos dos equipamentos, em medições de 2 minutos. Os resultados alcançados demonstraram que é viável o aproveitamento desta água, tendo em vista ter sido obtido um volume de $223,18 \mathrm{~m}^{3} / \mathrm{mês}$. Este volume supre em $100 \%$ a demanda não potável da rega de jardim. O LAFEPE não utilizada água da concessionária, portanto o aproveitamento não traz uma economia financeira direta, mas aponta benefícios ambientais que futuramente farão toda a diferença.

Palavras-chave: Vazão de condensado; Reúso de água; Redução de consumo.
\end{abstract}

\begin{abstract}
Over the years with the irrational use of water, there is a need to rethik the ways in which water resources are used, adopting sustainable practices that aim to guarantee the future of new generations to come. Ways to migitate impacts can be reuse and water use, which includes the use of water from air conditioning units. This work aims to evaluate the feasibility of using water from the air conditioning equipment of Pharmaceutical Laboratory of Pernambuco (LAFEPE). Thus, the LAFEPE solid waste buildin 1 was taken as the object of study, which has 10 Fancoil type appliances with a total capacity of 310,50 TR (refriferation ton). The measurements were made directly in the drains of the equipment, in measurements of 2 minutes. The results achieved demonstrated that it is feasible to use this water, considering that a volumo f 223,18 $\mathrm{m}^{3} / \mathrm{month}$ was obtained. This volume supplies $100 \%$ of the non-potable demand for Garden irrigation. LAFEPE does not use water from the concessionaire, so the use does not bring direct financial savings, but points to environmental benefits that in the future will make all the diference.
\end{abstract}

Keywords: Condensate flow; Water reuse; Consumption reduction.

\section{Resumen}

A lo largo de los años con el uso irracional del agua, existe la necesidad de repensar las formas en que se utilizan los recursos hídricos, adoptando prácticas sostenibles que tengan como objetivo garantizar el futuro de las nuevas gerenaciones por venir. Las formas de mitigar los impactos pueden ser la reutilización e el uso del agua, que incluye el uso de agua de las unidades de aire acondicionado. Este trabajo tiene como objetivo evaluar la viabilidade de utilizar agua de los equipos de aire acondicionado del Laboratorio Farmacéutico de Pernambuco (LAFEPE). Así, se tomó como objeto de estudio, el edificio 1 de residuos sólidos, que cuenta con 10 aparatos tipo Fancoil con una capacidade total de 310,50 TR (ton frigorífico). Las medidas se realizaron diretamente en los desagues del equipo, en medidas de 2 minutos. Los resultados obtenidos demonstraron que es factible utilizar esta agua, considerando que se obtuvo un volumen de 223,18 m³ $/$ ês. Este volumen abastece el $100 \%$ de la demanda no potable para Riego de jardines. El LAFEPE no usa 
agua de la concesionaria, por lo que el uso no trae ahorros económicos directos, pero apunta a benefícios ambientales que en el futuro marcarán la diferencia.

Palabras clave: Flujo de condesado; Reutilización de agua; Reducción del consumo.

\section{Introdução}

A água é um recurso crucial para existência da vida na terra. Assim, todas as formas de vida necessitam dela para a sobrevivência, sendo um dos recursos mais importante no planeta. Segundo Fortes et al. (2015), a água é importante para a manutenção da vida e indispensável para diversas atividades do ser humano, apresentando valores econômicos, sociais e culturais. Ao longo dos anos, com o uso irracional da água, iniciou-se a sentir os efeitos da escassez desse recurso em algumas regiões do planeta. De acordo com Bastos, Túlio e Franci (2015), essa problemática traz à tona uma necessidade de repensar as formas de uso desse recurso, adotando práticas mais sustentáveis, a fim de manter uma boa disponibilidade, ou seja, quantidade e qualidade para as gerações futuras.

De acordo com a ONU (2013), a demanda mundial vem crescendo significativamente nos últimos anos, de forma que se as tendências atuais se mantiverem, nas próximas décadas os países mais pobres sofrerão em aspectos como saúde humana e seus ecossistemas. Embora o Brasil disponha de uma das maiores reservas de água doce do mundo, os problemas referentes a escassez desse recurso natural são enfrentados em diversas regiões do país, em especial no semiárido nordestino, onde são encontrados municípios sob regime constante de racionamento da água (Sousa, et al., 2017). Assim, as formas sustentáveis de manejo da água são assuntos crescentes no Brasil e no mundo, como técnicas de uso, reúso e aproveitamento desse recurso. Dessa forma, torna-se necessária uma mudança radical na forma como a água é usada para evitar a escassez.

Segundo Silva (2015), o estado de Pernambuco sofre com problemas na gestão dos recursos hídricos e apresenta algumas regiões acometidas pela escassez de água em períodos de estiagem. Além disso, a Região Metropolitana do Recife sofre com crises de abastecimento, resultando em racionamento de água, visto que alguns locais são densamente povoados.

Algumas formas de amenizar tais impactos podem ser encontradas em soluções ambientais de reúso e aproveitamento hídrico, como: o reúso de águas servidas como lavatórios, máquina de lavar, entre outros; o aproveitamento proveniente das águas de chuva e também do condensado dos sistemas de ar condicionado. Todas, com um nível maior ou menor de tratamento, seriam de grande valia para a utilização não potável dentro de uma edificação como lavagem de pisos, rega de jardins, lavagem de carro, entre outros. Dessa forma, o estudo da produção de água do condensado dos aparelhos de ar condicionado, é uma das possíveis soluções de aproveitamento que pode ser avaliada dentro das edificações.

Mota et al. (2011), afirmam que esse aproveitamento da condensação produzida pelos condicionadores de ar depende da coleta eficiente de cada sistema de drenagem, de forma a conduzir o líquido para um sistema de armazenagem localizado na edificação.

Bastos e Calmon (2013) aplicaram um sistema que utiliza a água produzida pelos aparelhos de ar condicionado, utilizando-as nas descargas do banheiro em um edifício comercial também na cidade de Vitória com o objetivo de reduzir o consumo de água tratada, gerando assim uma economia para a edificação. De acordo com os autores, 137 equipamentos com capacidades diferentes produziram 4298,1 L/dia de água, trazendo assim economia para o empreendimento.

Loveless, et. al (2013) analisaram que muitas regiões do mundo têm alto potencial de produção de água condensada e que o volume gerado de água do condensado depende em grande parte da umidade relativa do ar, que por sua vez é dependente de padrões climáticos. A partir desse estudo, foram identificadas 4 regiões que sofrem de escassez hídricas e ao mesmo tempo tem um elevado potencial de produção de água condensada, são: Península arábica, África Ocidental, sudeste da Ásia, América Central e América do Sul.

Silva (2018) realizou uma análise do potencial de substituição do consumo de água potável, no prédio administrativo da Governadoria do Estado de Pernambuco. Nesse estudo a produção de água de ar condicionado foi estimada, com base em 
dados da literatura e o consumo da edificação com base no histórico de consumo da edificação, dos últimos 12 anos. A água coletada do sistema de ar condicionado seria direcionada para a rega de jardim, onde foi possível obter uma produção de $26,83 \mathrm{~m}^{3}$ de água condensada, equivalente a $8 \%$ do valor levantado de consumo por rega de jardim ao mês. A produção do sistema não supre a demanda, mas considerando o valor cobrado pela concessionária local, haveria uma economia anual de $\mathrm{R} \$ 2.865,46$.

Outros estudos relacionados ao aproveitamento de água de aparelhos de ar condicionado também foram realizados, porém com a temática voltada a análise qualitativa da água. É o caso de Cunha e Faria (2012) que realizaram um estudo em um sistema de ar condicionado, onde foram coletadas amostras ao longo de 5 meses, afim de analisar $\mathrm{pH}$, alcalinidade, cloretos, condutividade e dureza. Os valores obtidos foram comparados com os limites estabelecidos pela resolução 518/2004 do Ministério da Saúde (Brasil, 2004). É importante salientar que a Portaria foi revogada em 2011, onde alguns parâmetros foram alterados, passando a valer a Portaria 2.914/11 que atualmente foi substituída pela Consolidação 5 ou PRC nº 5 (Brasil, 2017).

No Brasil, ainda não existem normas específicas sobre o aproveitamento da água de condensação, porém existem leis que tratam sobre o assunto, as quais tiveram seu embasamento no incômodo que o gotejamento dos aparelhos de ar condicionado nas calçadas provocava nas pessoas que transitavam na via, como a Lei no 4892 (2000) em São Bernardo do Campo e a Lei ${ }^{\circ}$ 3396 (2002) em Limeira, ambos no estado de São Paulo; a Lei no 2 (1975) em Porto Alegre, no estado do Rio Grande do Sul. Mais recentemente, o estado de Pernambuco publicou a Lei $n^{\circ} 16.589$ (2019), que altera a Lei $n^{\circ} 14.572 / 2011$, e dispõe sobre a coleta e o reaproveitamento da água do sistema de climatização das edificações como uma das ações de reaproveitamento das águas nas edificações do Estado.

Segundo Soares (2017), a falta de estudos sobre o assunto está relacionada com a análise de grande parte da população de que os aparelhos de ar condicionado não produzem uma vazão expressiva. Em locais onde estão dispostos poucos aparelhos e de potências pequenas, geralmente não apresentam uma produção expressiva, porém em prédios onde se encontram grandes quantidades de aparelhos de potências elevadas, a produção torna-se relevante.

O objetivo deste trabalho é avaliar a viabilidade técnica do aproveitamento de água produzida pelos aparelhos de ar condicionado para fins não potáveis em prédio público no estado de Pernambuco, através da obtenção do volume de água condensada dos aparelhos de ar condicionado do prédio público estudado e da estimativa das demandas hídricas não potáveis da edificação que poderia utilizar a água proveniente dos aparelhos de ar condicionado.

\section{Metodologia}

Este trabalho se deu por meio da realização de consultas documentais e bibliográficas pertinentes ao tema, pesquisas de campo, coletas de dados e informações relevantes ao estudo. Sendo assim, a pesquisa apresentou uma abordagem predominantemente quantitativa, através de uma pesquisa de campo, tendo em vista o local de desenvolvimento do estudo ter uma grande estrutura física.

Este estudo buscou suporte metodológicos em algumas bibliografias presentes na literatura, sendo elas: Soares (2017), Ferraz (2017), Melo (2020) e Prado, Soares e Silva (2020), as quais também analisaram o aproveitamento de água dos aparelhos de ar condicionado em prédios com outras tipologias no estado de Pernambuco.

Diante disso, ela foi realizada nas seguintes etapas:

(a) Seleção do prédio a ser estudado;

(b) Levantamento de dados do prédio estudado;

(c) Cálculo do volume de água condensada dos aparelhos;

(d) Estimativa das demandas hídricas não potáveis;

(e) Análise da viabilidade do uso de água condensada. 


\subsection{Seleção do prédio a ser estudado}

Para a escolha do prédio de estudo, foram levadas algumas considerações:

- O prédio ser de propriedade pública, de forma a trazer resultados que venham a repercutir de forma mais direta em toda a sociedade;

- Ter uma facilidade de acesso a instalações e comunicação com a administração, para que fosse possível o acesso para medições, coletas de dados e informações;

- Infraestrutura da edificação favorável para a realização das medições e recolhimento de dados.

\subsection{Levantamento de dados do prédio a ser estudado}

Os dados do prédio foram obtidos através de visita técnica para o recolhimento de dados como: caracterização do sistema de ar condicionado e seus aparelhos; quantidade de aparelhos do sistema de ar condicionado e suas potencias; etc. Outras informações foram recolhidas através da gestão da instituição que acompanharam a visita nas dependências do edifício.

\subsection{Cálculo do volume de água condensada dos aparelhos}

Para o levantamento do volume de condensado do sistema foram utilizados os materiais: proveta graduada; balde e cronômetro. Para a obtenção dos volumes foram feitas medições, onde, um balde era colocado no dreno do aparelho, coletando a água do condensado por um período de 2 minutos. Após isso, a água era transferida para a proveta para que o volume fosse mensurado. $\mathrm{O}$ processo se repetiu 3 vezes em cada aparelho, sendo considerada a média das 3 medições. O tempo de operação do prédio é de 24 horas. Assim, foram considerados 1440 minutos para a determinação da vazão diária. Foi utilizada a equação (1), conforme Melo (2020), para determinação dessa vazão. A equação 1 foi utilizada para estimar a quantidade diária de água produzida e a equação 2 a quantidade mensal de condensado produzido pelo equipamento de ar condicionado.

$$
\mathrm{QDIA}=\frac{\mathrm{VCP} \times \mathrm{TF}}{\mathrm{TM}}
$$$$
\text { Equação (1) }
$$

QDIA = Quantidade de água produzida durante um dia;

$\mathrm{VCP}=$ Volume médio de água do condensado produzida durante um período;

$\mathrm{TF}=$ Tempo de funcionamento do equipamento;

$\mathrm{TM}=$ Tempo de medição.

$$
\text { QMÊS = QDIA x DM Equação (2) }
$$

QMÊS = Quantidade de água produzida durante o mês;

QDIA = Quantidade de água produzida durante um dia;

$\mathrm{DM}=$ Dias de funcionamento no mês.

\subsection{Estimativas das demandas hídricas não potáveis da edificação}

A partir de monitoramentos realizados para se levantar demandas hídricas não potáveis no prédio, que poderiam ser atendidas com água produzida pelos sistemas de ar condicionado, identificou-se que a principal demanda não potável da instituição foi a rega de jardim. Além disso, outras demandas foram encontradas, mas que não poderiam ser totalmente atendidas por essa água, como por exemplo a demanda da torre de resfriamento, que é um sistema de água gelada para resfriar 
os Chillers do sistema de refrigeração. As áreas de jardim foram estimadas com o auxílio da ferramenta de imagens de satélite e a ferramenta "régua" do Google Maps.

O local de estudo conta com um sistema de captação, tratamento e distribuição de água de responsabilidade própria, não utilizando do abastecimento da Companhia Pernambucana de Saneamento (COMPESA). Toda demanda do parque é feita através de um poço com capacidade de $36 \mathrm{~m}^{3} / \mathrm{h}$.

\subsection{Análise da viabilidade do uso de água condensada}

Após estimar a produção de água do sistema de climatização do prédio estudado, foi realizada uma análise comparativa em relação a demanda de água consumida na rega de jardim da instituição. Assim, foi possível fazer uma análise de viabilidade do aproveitamento das águas dos sistemas de refrigeração.

\section{Resultados e Discussão}

\subsection{Seleção do prédio estudado}

O Laboratório Farmacêutico de Pernambuco - LAFEPE foi criado em 1965, com autorização legislativa do Decreto Estadual $n^{\circ} 1.180$ de 04 de janeiro de 1966, no Governo de Miguel Arraes. Hoje, desenvolve, produz e comercializa medicamentos e óculos de grau. Possui sede no bairro de Dois Irmãos, no município do Recife. Atualmente possui uma estrutura composta por quatro plantas fabris, das quais três são de sólidos (sólidos 1, sólidos 2 e Antirretrovirais) e uma de líquidos. Isso representa uma área construída de quase $26 \mathrm{mil} \mathrm{m}^{2}$. A Figura 1 apresenta a localização do LAFEPE, juntamente com seus principais prédios.

Figura 1 - Vista aérea da planta fabril e seus principais prédios.

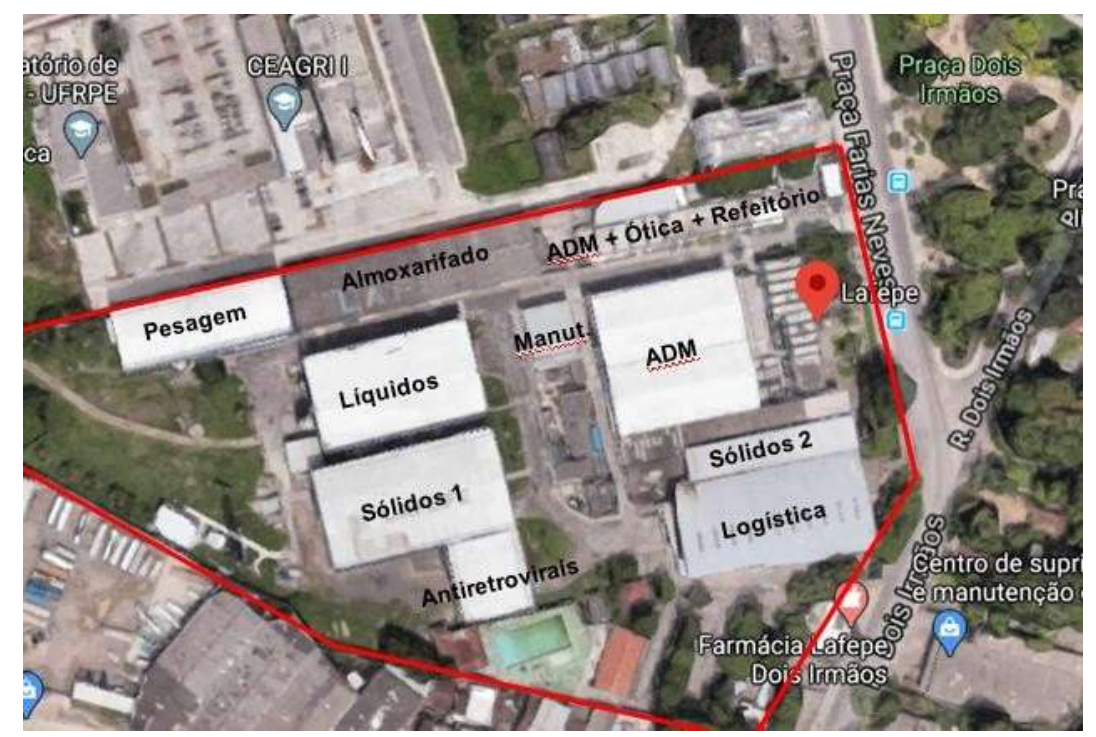

Fonte: Criado pelos autores a partir do Google Maps.

Para este estudo, foi escolhido o prédio de sólidos 1 para realização da análise do potencial de água do condensado que os equipamentos instalados em seu sistema produzem. Essa escolha se deu pelo fato de, dentre os prédios voltados para a produção, este é o que está em plena operação na fabricação de medicamentos. Além disso, os equipamentos nele instalado possuem altas capacidades térmicas, o que por hipótese, sugere-se que geram mais água condensada. 


\subsection{Levantamento de dados do prédio a ser estudado}

Os equipamentos instalados no prédio de Sólidos 1 são do tipo Fancoil, que são equipamentos que se utilizam de um sistema de água gelada para climatizar os ambientes. A água é gelada no chiller e circulada por bombas dentro do sistema, onde o líquido funciona como fluido refrigerante. Os Fancoils recebem a água gelada a aproximadamente $7^{\circ} \mathrm{C}$ e a devolve a cerca de $12^{\circ} \mathrm{C}$ para o Chiller. A figura 2 apresenta o tipo de equipamento estudado.

Figura 2 - Equipamento do modelo Fancoil estudado.

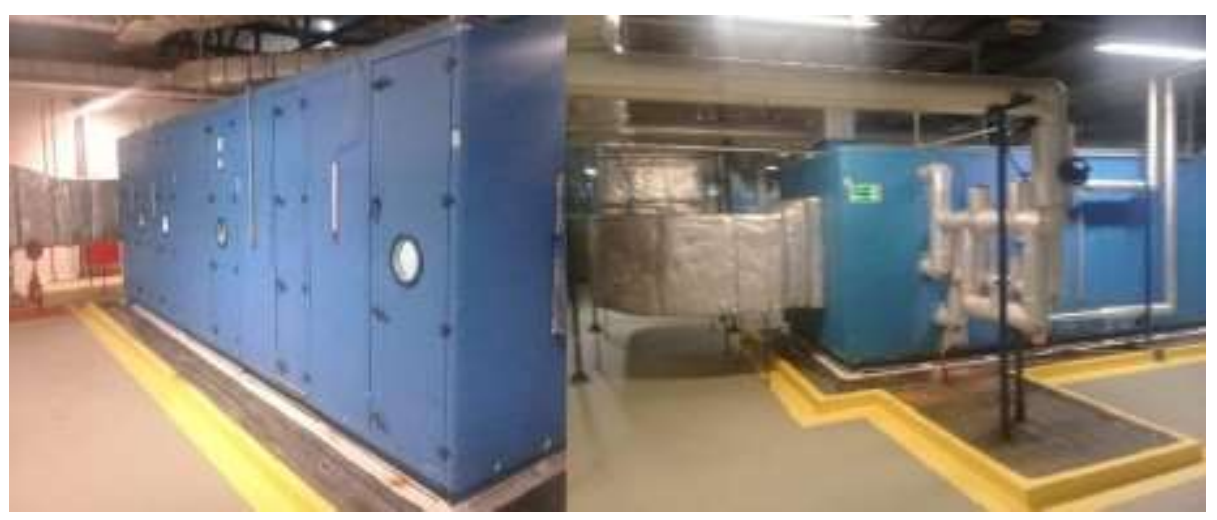

Fonte: Autores.

Cada Fancoil possui uma capacidade térmica determinada pelo calculista. A unidade de 1 BTU é a quantidade de energia utilizada para provocar uma elevação de temperatura $\left(59,5^{\circ} \mathrm{F}\right.$ a $\left.60,5^{\circ} \mathrm{F}\right)$ em uma libra de água, sob pressão constante de 1 atm (TECNOAR, 2010). A unidade mede a quantidade de calor de um ambiente fechado e que precisa ser retirada para atingir o conforto desejado. Existe também a unidade de tonelada de refrigeração (TR) que geralmente é utilizada em aparelhos de maior capacidade para determinar sua potência. 1 TR equivale a 12.000 BTU's.

O sistema do objeto de estudo conta com 10 aparelhos do tipo Fan coil, responsáveis por atender as instalações do próprio prédio, com potência entre 5 e 105 TR. Os aparelhos são nomeados por UTA (unidade de tratamento de ar). As capacidades térmicas dos aparelhos são apresentadas no Quadro 1.

Quadro 1 - Potências térmicas dos aparelhos do sistema estudado.

\begin{tabular}{|c|c|c|c|c|c|c|c|c|c|c|}
\hline APARELHOS & $\begin{array}{c}\text { UTA } \\
01\end{array}$ & $\begin{array}{c}\text { UTA } \\
02\end{array}$ & $\begin{array}{c}\text { UTA } \\
03\end{array}$ & $\begin{array}{c}\text { UTA } \\
04\end{array}$ & $\begin{array}{c}\text { UTA } \\
05\end{array}$ & UTA 06 & $\begin{array}{c}\text { UTA } \\
07\end{array}$ & $\begin{array}{c}\text { UTA } \\
08\end{array}$ & $\begin{array}{c}\text { UTA } \\
09\end{array}$ & $\begin{array}{c}\text { UTA } \\
10\end{array}$ \\
\hline $\begin{array}{c}\text { CAPACIDAD } \\
\text { E } \\
\text { TERMICA } \\
\text { (TR) }\end{array}$ & 38,33 & 41,54 & 53,98 & 5,27 & 9,12 & 105,44 & 14,30 & 12,52 & 15 & 15 \\
\hline $\begin{array}{c}\text { CAPACIDAD } \\
\text { E } \\
\text { TERMICA } \\
\text { (BTU) }\end{array}$ & $\begin{array}{c}459.96 \\
0\end{array}$ & $\begin{array}{c}498.48 \\
0\end{array}$ & $\begin{array}{c}647.76 \\
0\end{array}$ & 63.240 & $\begin{array}{c}109.44 \\
0\end{array}$ & $\begin{array}{l}1.265 .28 \\
0\end{array}$ & $\begin{array}{c}171.60 \\
0\end{array}$ & $\begin{array}{c}150.24 \\
0\end{array}$ & $\begin{array}{c}180.00 \\
0\end{array}$ & $\begin{array}{c}180.00 \\
0\end{array}$ \\
\hline
\end{tabular}

Fonte: Autores. a partir de visita a edificação.

O sistema responsável por atender o prédio estudado apresenta uma capacidade térmica total de 3.726.000 BTU's ou 310,50 TR's.

Nos equipamentos do tipo Fancoil existe um sistema de drenagem do condensado já instalado, que conta com tubulações e canaletas que escoam todo o fluido gerado para serem destinados ao sistema de drenagem, conforme Figura 3 mostrada abaixo. 
Figura 3 - Sistema de drenagem dos equipamentos

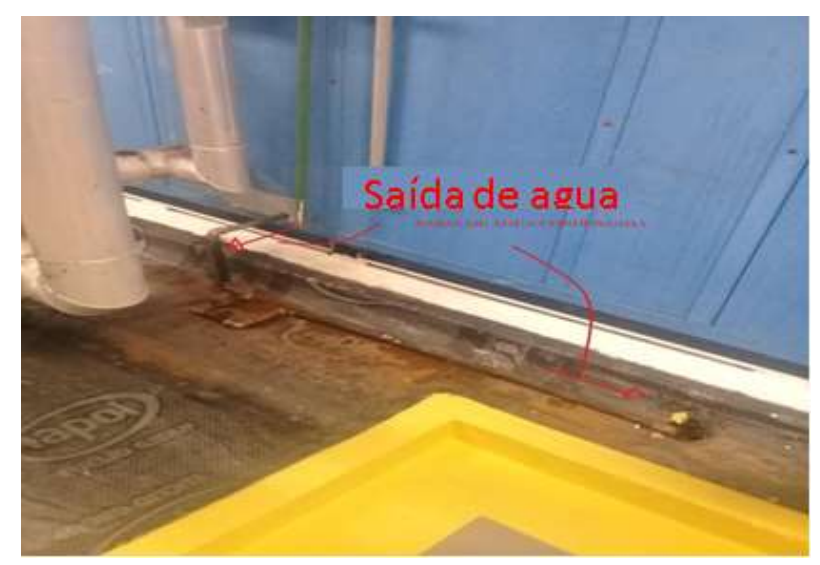

Fonte: Autores.

\subsection{Cálculo do volume de água condensada dos aparelhos}

A quantidade de água produzida em cada aparelho foi obtida de forma direta, fazendo- se medições de 2 minutos e extrapolando os valores obtidos nesse período. A Tabela 1 mostra os valores médios obtidos nas medições de 2 minutos, assim como sua vazão diária e mensal.

Tabela 1 - Água condensada produzida.

\begin{tabular}{|c|c|c|c|c|c|c|c|c|c|c|c|}
\hline $\begin{array}{l}\text { APARELHO } \\
\text { S }\end{array}$ & UTA1 & UTA 2 & UTA3 & UTA 4 & $\begin{array}{c}\text { UTA } \\
5 \\
\end{array}$ & $\begin{array}{c}\text { UTA } \\
6 \\
\end{array}$ & UTA7 & $\begin{array}{c}\text { UTA } \\
8 \\
\end{array}$ & UTA 9 & $\begin{array}{c}\text { UTA } \\
10 \\
\end{array}$ & TOTAL \\
\hline $\begin{array}{l}\text { Média de } \\
\text { volume } \\
\text { coletada em } \\
2 \text { minutos } \\
\text { (litros) }\end{array}$ & 1,01 & 2,47 & 3,21 & 0,16 & 0,18 & 0,22 & 0,50 & 0,49 & 1,03 & 1,03 & - \\
\hline $\begin{array}{c}\text { Vazão } \\
\text { mensal } \\
\text { produzida } \\
(1 / \text { dia })\end{array}$ & 724,97 & $\begin{array}{c}1778,4 \\
0\end{array}$ & 2313 & 118,8 & 129,6 & 162 & 361,20 & $\begin{array}{c}357,5 \\
5\end{array}$ & 747 & 747 & 7439.52 \\
\hline $\begin{array}{c}\text { Vazão } \\
\text { mensal } \\
\text { produzida } \\
\left(\mathrm{m}^{3} / \mathrm{mês}\right)\end{array}$ & 21,77 & 53,35 & 69,39 & 3,56 & 3,88 & 4,86 & 10,83 & 10,72 & 22,41 & 22,41 & 223,18 \\
\hline
\end{tabular}

Fonte: Autores.

Os valores diários de volume de água produzido pelos aparelhos ligados são aproximadamente 7439,52 Litros de água. Assim, ao longo de 30 dias acumula um volume de 223,18 $\mathrm{m}^{3}$, que é considerado um elevado potencial de reaproveitamento. Ao longo de um ano podemos chegar em um volume de $2678,16 \mathrm{~m}^{3}$ de água.

A UTA 9 no momento da coleta de dados não estava funcionando, desta forma não foi possível fazer as medições. A sua vazão produzida foi adotada igual a UTA10, que se trata de um aparelho de mesma capacidade e operando em condições semelhantes.

Já a UTA 6 apresentou um volume produzido abaixo dos outros equipamentos de menor capacidade, o que indica alguma falha no sistema de drenagem ou na própria refrigeração. Estudos apontam que a produção de condensado deste aparelho seria muito maior do que o medido. Isso indica que em perfeitas condições dos equipamentos, a vazão total produzida poderia ser ainda maior. 


\subsection{Estimativa das demandas hídricas não potáveis}

Segundo Tomas (2003), o consumo de água para a atividade de rega de jardim é $2 \mathrm{Litros} / \mathrm{dia} / \mathrm{m}^{2}$. A instituição tem uma rotina de rega de 4 dias por semana, sendo assim considerados 16 dias mensais. O parque fabril possui uma área verde de 2.369,51 $\mathrm{m}^{2}$, calculada baseada em imagens do Google Maps, onde o volume mensal consumido para rega de jardins encontrado no estudo foi de $37,91 \mathrm{~m}^{3}$. Parte do jardim é mostrado na Figura 4.

Figura 4 - Jardim em frente ao prédio de sólidos 1 - LAFEPE.

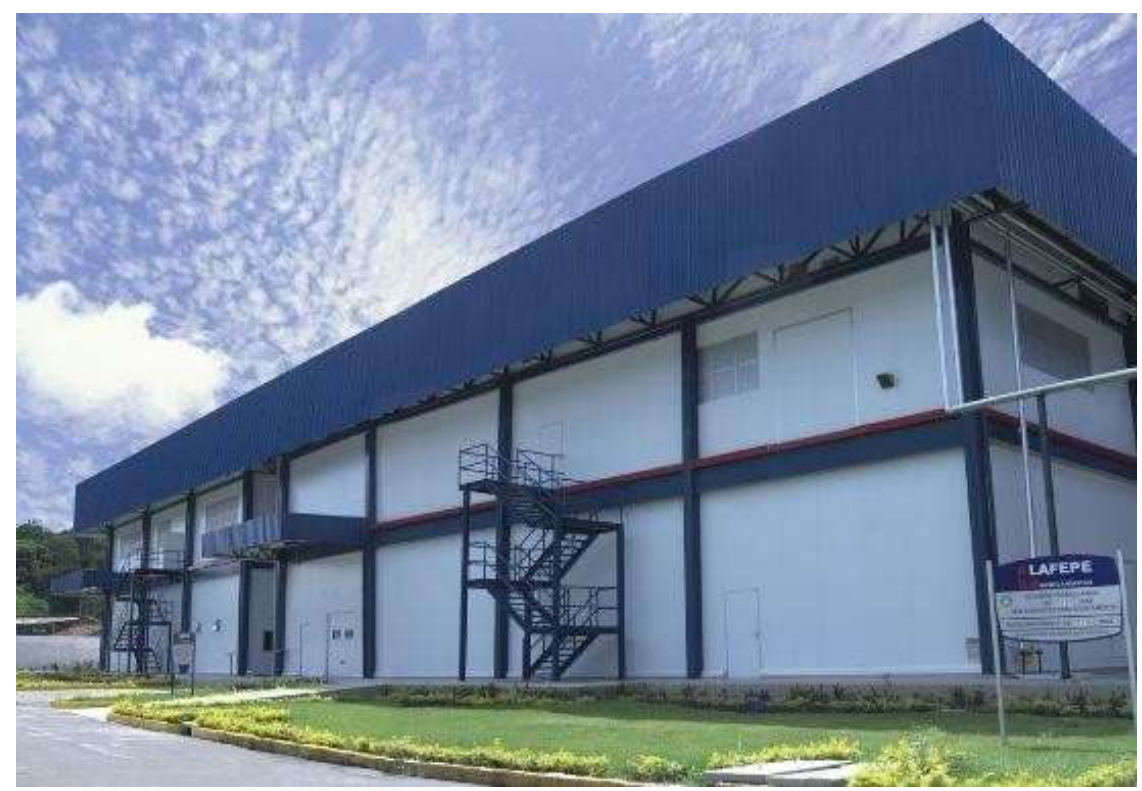

Fonte: Autores, a partir de visita ao local.

\subsection{Análise da viabilidade do uso de água condensada}

A demanda de água para rega de Jardim da instituição corresponde a aproximadamente 17\% do produzido pelo sistema de ar condicionado. Desta forma, é possível atender toda a demanda e ter uma sobra considerável.

Esse valor excedente pode ser usado para amortizar o uso de recursos naturais em outras atividades de grande consumo, como a torre de Resfriamento, que é um sistema de água gelada para resfriar os Chillers do sistema de refrigeração, que necessita de uma demanda hídrica de $15 \mathrm{~m}^{3} /$ dia.

\section{Conclusão}

Essa pesquisa trouxe contribuições para a discussão de que existem diversos fatores que influenciam na produção de água condensada dos aparelhos, entre esses estão os fatores climáticos da região, a capacidade dos aparelhos, a manutenção correta dos aparelhos, entre outras.

Diante dos resultados obtidos torna-se viável o aproveitamento da água condensada do sistema de refrigeração do prédio de resíduos sólidos 1 do LAFEPE. O local apresentou uma produção de $223,18 \mathrm{~m} / \mathrm{mês}$ e a demanda calculada para a rega de jardim foi de $37,91 \mathrm{~m}^{3} /$ mês, sendo totalmente atendida e gerando uma redução do uso de água potável dos lençóis freáticos locais. Apesar da prática não gerar uma redução financeira para a instituição, é inegável que em aspectos ambientais ela traz vantagens inestimáveis.

É importante ressaltar que a água produzida que não fosse utilizada na rega de jardim poderia ser aproveitada para diversas outras demandas não potáveis presentes na instituição, como a lavagem de piso ou servindo outros equipamentos de alta demanda hídrica, como forma de amortizar o consumo. Isso poderia se dar mediante o armazenamento dessa água em um 
ou mais reservatórios, ligando-os aos drenos do sistema de ar condicionado. Destaca-se que o prédio já possui sistema de drenagem do condensado produzido pelos aparelhos de ar condicionado, o que contribui para um menor custo de implementação do projeto de aproveitamento dessa água.

Esse estudo pode ser estendido a outras instituições, verificando as características da produção de água condensada nas instituições, de forma a contribuir para o uso e conservação sustentável de água, gerando uma redução na demanda hídrica do estado.

Por fim, para trabalhos futuros sugere-se que sejam feitas medidas da água produzida pelos aparelhos de ar condicionado em outros meses do ano, levando em consideração os diferentes comportamentos para o inverno e o verão, bem como avaliação da produção de água drenada em função das condições do filtro de ar condicionado e idade dos aparelhos monitorados. Por último, recomenda-se nas próximas pesquisas a avaliação dos custos de implantação de reservatório e tubulação para a coleta desta água.

\section{Referências}

Bastos, C. S. \& Calmon, J. L. (2013). Uso de água residual do ar condicionado e de água pluvial como gestão da oferta em uma edificação comercial: estudo de caso. Hábitat Sustentable. 3(2), 66-74.

Bastos, C., Túlio, S. \& Franci, R. Gestão da água em edificações através do aproveitamento de condensação do sistema de ar-condicionado: um exemplo em Vitória, Brasil. Euro Elecs. 1, 1197-1202.

Cunha, S. O. \& Faria, R. A. P. G. (2012). Caracterização quali-quantitativa da água da condensadora de aparelhos de ar condicionado. III. Congresso Brasileiro de Gestão Ambiental. Instituto Brasileiro de Estudos Ambientais. Goiânia, Goiás 1, 1-3. http://www.ibeas.org.br/congresso/Trabalhos2012/IX-002.pdf

Fortes, P. D., Jardim, P. W. C. F. P. M. G. \& Fernandes, J. G. (2015). Aproveitamento de água proveniente de aparelhos de ar condicionado. XII Simpósio de Excelência em Gestão e Tecnologia. https://www.aedb.br/seget/arquivos/artigos15/37822430.pdf

Ferraz, K. A. (2017). Otimização do uso de condicionadores de ar com ênfase na vazão de água de condensado e consumo energético: estudo de caso em uma instituição de ensino em Recife - PE. 68. Dissertação (Mestrado Profissional em Tecnologia Ambiental) - Associação Instituto de Tecnologia de Pernambuco ITEP, Recife, PE, Brasil.

Loveless, K. J., Farooq, A. \& Ghaffour, N. (2013). Collection of Condensate Water: Global Potential and Water Quality Impacts. Water Resources Management. 27(5), 1351-61.

Lei n. 4892 de 19 de julho de 2000 (2000). Dispõe sobre o disciplinamento para instalação de aparelhos de ar condicionado e dá outras providências. Câmara Municipal. São Bernardo do Campo, SP.

Lei n. 16.584 de 10 de junho de 2019 (2019). Estabelece normas para o uso racional e reaproveitamento das águas nas edificações do Estado de Pernambuco e dá outras providências. Altera a Lei no 14.572 de 27 de dezembro de 2011. Diário Oficial do Estado. Recife, PE.

Lei n. 3.396 de 07 de junho de 2002 (2002). Dispõe sobre a obrigatoriedade dos proprietários de aparelhos de ar condicionado individual e/ou coletivos de colocarem coletores de água provenientes de condensação e dá outras providências. Câmara Municipal. Limeira, SP.

Lei Complementarn. 12 de 07 de janeiro de 1975 (1975). Institui posturas para o Município de Porto Alegre e dá outas providências. Diário Oficial do Município. Porto Alegre, RS.

Melo, A. J. N. (2020). Aproveitamento da água gerada por condicionadores de ar para fins não potáveis: estudo de caso em um hospital na cidade do Recife. 137. Dissertação (Mestrado em Engenharia Civil). Universidade de Pernambuco. Recife, PE, Brasil

Mota, T. R., Oliveira, D. M. \& Inada, P. (2011). Reutilização da Água dos Aparelhos de Ar Condicionado em uma Escola de Ensino Médio no município de Umuarama-PR. Encontro Internacional de Produção Científica. http://www.cesumar.br/prppge/pesquisa/epcc2011/anais/thatiane_rodrigues_mota_2.pdf

ONU. (2013). A Onu e a Água. https://nacoesunidas.org/acao/agua/

Portaria MS n. 518 de 25 de março de 2004 (2004). Estabelece os procedimentos e responsabilidades relativos ao controle e vigilância da qualidade da água para consumo humano e seu padrão de potabilidade e dá outras providências. Diário Oficial da União. Brasília, DF.

Portaria de Consolidação n. 5, anexo XX de 28 de setembro de 2017 (2017). Dispõe sobre o controle e vigilância da qualidade da água para o consumo humano e seu padrão de potabilidade. Diário Oficial da União. Brasília, DF.

Prado, A. R. M. do, Soares, A. E. P., \& Silva, S. R. da. (2020). Análise técnico-econômica da utilização de água de condensação para fins não potáveis em um campus universitário. Revista Nacional De Gerenciamento De Cidades, 8(65). https://doi.org/10.17271/2318847286520202588

Silva, A. F. A. (2015). Indicadores de consumo de água de prédios públicos administrativos em Pernambuco. 136. Trabalho de Conclusão de Curso (Engenharia Civil). Universidade de Pernambuco. Recife, PE, Brasil. 
Research, Society and Development, v. 10, n. 16, e85101623372, 2021

(CC BY 4.0) | ISSN 2525-3409 | DOI: http://dx.doi.org/10.33448/rsd-v10i16.23372

Silva, T. L. (2018). Alternativas de redução do consumo de água potável no palácio do governo de Pernambuco. 84. Trabalho de Conclusão de Curso (Engenharia Civil). Universidade de Pernambuco. Recife, PE, Brasil

Soares, M. C. D. M. (2017). Reúso de água dos aparelhos de ar condicionado para fins não potáveis em prédio público administrativo. 69 . Trabalho de Conclusão de Curso (Engenharia Civil). Universidade de Pernambuco. Recife, PE, Brasil.

Sousa, I. M. T. et al. (2017). Estudo da viabilidade reúso da água proveniente de aparelho de ar condicionado. Anais da Feira Nacional de Saneamento e Meio Ambiente (FENASAN), São Paulo, SP, Brasil.

Tecnoar. (2010). Informações ar condicionado. https://www.tecnoar.com.br/informacoes.php

Tomaz, P. (2003). Aproveitamento de Água de Chuva para Áreas Urbanas e Fins não Potáveis. (2a ed.), Navegar Editora. 